This is the author's final, peer-reviewed manuscript as accepted for publication. The publisher-formatted version may be available through the publisher's web site or your institution's library.

\title{
Systemic perspectives on Intimate Partner Violence treatment
}

Sandra M. Stith, Eric E. McCollum, Yvonne Amanor-Boadu, Douglas Smith

\section{How to cite this manuscript}

If you make reference to this version of the manuscript, use the following information:

Stith, S. M., McCollum, E. E., Amanor-Boadu, Y., \& Smith, D. (2012). Systemic perspectives on Intimate Partner Violence treatment. Retrieved from http://krex.ksu.edu

\section{Published Version Information}

Citation: Stith, S. M., McCollum, E. E., Amanor-Boadu, Y., \& Smith, D. (2012). Systemic perspectives on Intimate Partner Violence treatment. Journal of Marital and Family Therapy, 38(1), 220-240.

Copyright: ( 2011 American Association for Marriage and Family Therapy

Digital Object Identifier (DOI): doi:10.1111/j.1752-0606.2011.00245.x

Publisher's Link: http://onlinelibrary.wiley.com/doi/10.1111/j.17520606.2011.00245.x/abstract 


\title{
Systemic Perspectives on Intimate Partner Violence Treatment
}

\author{
Sandra M. Stith \\ Kansas State University \\ Eric E. McCollum \\ Virginia Tech \\ Yvonne Amanor-Boadu \\ Kansas State University
}

\section{A Clinician Responds}

\section{Douglas Smith}

Texas Tech University 
Treatment of Intimate Partner Violence

Systemic Perspectives on Intimate Partner Violence Treatment

\begin{abstract}
This paper reviews changes in the research literature on Intimate Partner Violence (IPV) since our earlier review (Stith, Rosen, \& McCollum, 2003). A rationale for systemic treatment of IPV has emerged from research that has continued to document the limited effectiveness of single gender treatment approaches for offenders and that has identified sub-types of abusive relationships, including Situational Couple Violence, that often includes the reciprocal use of violence. Consistent findings from the available outcome research have demonstrated that for carefully screened couples who choose to stay together, systemic interventions decrease incidences of IPV and decrease the risk factors for IPV with no increase in risk. Implications for research and treatment are offered.
\end{abstract}


Systemic Perspectives on Intimate Partner Violence Treatment

This paper reviews changes in the research literature on Intimate Partner Violence (IPV) since our earlier review (Stith, Rosen, \& McCollum, 2003). A number of changes have occurred in the way we view IPV as well as in our knowledge about existing and developing treatment approaches. In this manuscript we describe the research that has led to these changes, as we seek to understand and deal with what remains a serious and costly social problem. Since there is a very limited amount of research on violence in same sex relationships, and no research on the effectiveness of treatment approaches for same sex couples, the research that is reviewed here is reflective of that limitation.

\section{An Evolving Understanding of IPV}

As a result of research in the field, our understanding of IPV is beginning to broaden and change. Traditionally, IPV has been seen through a feminist paradigm and understood to be the expression of men's power over women, occurring in intimate heterosexual relationships, and supported by a patriarchal culture. Violence was considered a male phenomenon with women either remaining solely victims or assaulting their male partners in self defense. Violence was also seen as the primary problem with co-existing issues often seen as distractions that helped men evade responsibility for their violence. The responsibility for violence was unilaterally men's while the costs were unilaterally women's and the focus of intervention was to end violence specifically against women.

Evidence for this view of IPV came from studies using criminal justice and shelterseeking populations and showed considerable gender-asymmetry (i.e. many more men than women are arrested and many more women than men seek shelter in domestic violence victim 
shelters). However, this view was challenged as research using community samples began to be conducted. Although research examining arrested offenders or victims seeking shelter continues to show dramatic gender-asymmetry, community-based studies find that IPV perpetration and victimization may be more gender-symmetrical than we previously thought with participants reporting male perpetrated, female perpetrated, and reciprocally perpetrated violence. Whitaker, Haileyesus, Swahm and Saltzman (2007), for instance, analyzed data on 11,370 US adults aged 18 to 28 from the 2001 National Longitudinal Study of Adolescent Health and found almost 24\% of all relationships had some violence. Interestingly, this study found that half of those relationships were reciprocally violent; that is, both partners assaulted each other. Furthermore, in those relationships where the violence was unilateral, women were the perpetrators in more than $70 \%$ of the cases. Methods used to assess violence, including sampling strategies, influence prevalence rates, yet, it is also becoming clearer that both men and women perpetrate IPV. Family therapists need to focus our efforts not only on ending violence against women but on ending all forms of violence in relationships.

Not only has our understanding of the high prevalence of male-perpetrated, femaleperpetrated, and reciprocal violence increased in the past decade, we are beginning to understand more about the impact of violence on both men and women. Archer (2000), in a meta-analysis, found that while more women than men reported perpetrating violence, sixty-two percent of those injured by an intimate partner were women. Tjaden (2000) found that $26.4 \%$ of male IPV victims and $32.6 \%$ of the female victims reported that their partner threatened to harm or kill them although female victims were twice as likely to report being fearful of bodily injury or death than male victims (44.7\% vs. 19.6\%). While the assumption might be that male perpetrated violence results in more actual danger, Whitaker, et al. (2007), found, in fact, that 
reciprocal IPV was associated with greater injury than was nonreciprocal IPV regardless of the gender of the perpetrator.

Only a few studies have compared mental health outcomes of IPV victimization for males and females. Afifi, et al. (2009) used data available from the U.S. National Comorbidity Survey Replication (NCS-R) study to examine the psychological effects of male and female IPV victimization. They reported that IPV was associated with poor mental health outcomes for both men and women, although women experienced a wider range of problems than did males. Male victims of IPV were more likely than males in nonviolent relationships to experience externalizing disorders, including disruptive behavior disorders and substance use disorders. Female victims of IPV were more likely than females in nonviolent relationships to experience both externalizing and internalizing disorders (anxiety disorders) as well as suicidal ideation. Other research has supported these findings. Using a subsample of 7,395 married and cohabiting heterosexual couples drawn from Wave 1 of the National Survey of Families and Households, Anderson (2004) found that although IPV is associated with negative health consequences for both women and men, it is associated with significantly more depression and substance abuse for women. While the experience of victimization may have differing impacts on men than on women, it is important to recognize that both men and women are injured and are psychologically impacted by victimization. As family therapists become more aware that IPV is not nearly as gender asymmetrical as we once thought, the importance of providing treatment for both partners in an ongoing committed relationship becomes more apparent.

Our understanding of IPV has been further expanded as we have also begun to examine different typologies of violence - both types of violent offenders and types of violent relationships. One of the most widely researched typologies of violent relationships was 
developed by Johnson and Ferraro (Johnson, 2006; Johnson \& Ferraro, 2000) who identified four types of violent heterosexual couples: those experiencing "situational couple violence," “intimate terrorism,” “violent resistance,” and “mutual violent control.” Intimate terrorism generally involves unilateral violence and includes a high level of coercive control. In contrast, situational violence is more likely to be bilateral and involves conflict over a particular issue. Violent resistance involves violence that is enacted in order to resist intimate terrorism, and may have the primary motive of wanting to protect oneself, or be the result of an expression of anger or resistance to a controlling partner. Mutual violent control includes two equally coercive partners engaged in a struggle for control of the relationship. Situational violence is hypothesized to be the most prevalent type of relationship violence, particularly within samples from the general population, and in couples seeking conjoint therapy (Simpson, Doss, Wheeler, \& Christensen, 2007). In fact, Johnson (2006), when describing situational violence suggested that, “The core problem is one of communication skill deficiencies for which an individual compensates with verbal aggression that then escalates into violence” (p. 18).

Not only does the relational context of violence vary, the characteristics of those who are violent are not the same. There is growing consensus that two major types of male perpetrators exist - those described as "characterological” and those described as "situational” (Babcock, Canady, Graham, \& Schart, 2007). For characterological perpetrators, violence is part of an overall effort to dominate and control a partner and violence is not necessarily limited to the family. Situational perpetrators, on the other hand, tend to be in relationships in which there is more likely to be reciprocal violence and where violence serves to exert control over specific interactions, rather than as part of an overarching pattern of domination. 
While attention has been given to differentiating types of male perpetrators of violence for some time, scholars are now beginning to look at typologies of female offenders (Babcock, 2003; Swan, 2002). Babcock’s work is illustrative. She studied 52 women referred to a treatment program for female violence. Participants reported their own use of physical and psychological aggression, reasons for violence, particularly the use of instrumental violence or coercive control, or use of self-defense, as well as trauma symptoms and background variables including history of experiencing or witnessing abuse in families of origin, and history of arrest for domestic violence or nondomestic violence charges. Based on these factors, Babcock classified 50\% of women as Generally Violent (GV) and 50\% as Partner Only Violent (PO). Those classified as GV reported perpetrating more psychological and physical abuse, causing more injury in the past year, and a higher frequency of severe violent acts (e.g. "beating up” a partner) than did PO women. Motivations for use of violence differed between groups, with GV women more likely than PO women to report that their violence was because "he was asking for it”, because they "lost control”, were "frustrated”, or "to push his buttons.” Specific motivations of PO women were not identified, though it was noted that they were not more likely to use violence in self-defense, as was hypothesized. Finally, while there were no differences between groups in severity of the partner's use of violence, all women reported that their partners were more severely violent than they were in the past year.

Studies of male and female typologies show some similarities and argue for different types of interventions to address differences in the use of violence (Babcock, et al., 2007). For offenders who are violent within their family but are not generally violent, or for those who are engaged in Situational Couple Violence, systemic treatments may be called for. For those presenting with characterological violence or intimate terrorism, or a history of violence outside 
the family, individual and gender-specific group treatments may be more appropriate because of safety concerns regarding the existence of more severe forms of violence and patterns of coercive control in those experiencing intimate terrorism. It is assumed that the use of systemic treatments in these cases would pose a greater risk to victims' safety, though again, because of safety concerns, there has not been any research to test the effectiveness of systemic interventions for those types of offenders.

Co-occurring Substance Abuse

Despite the traditional view that violence should be the only focus of intervention, we are beginning to understand that violence often co-occurs with other significant problems that deserve attention, particularly substance abuse. Previously seen as an excuse to justify men’s assaults on women, a large body of research has found a relationship between IPV and substance abuse in both clinical and non-clinical samples. White and Chen (2002) conducted a longitudinal study of 725 individuals and found that problem drinking significantly predicted IPV perpetration and victimization for both men and women. In addition, the United States Department of Justice (Justice, 1998) suggests that two-thirds of incidents of IPV involve alcohol. Substance abuse among IPV perpetrators ranges from 40-92\%, depending on the study examined (Smith Stover, Meadows, \& Kaufman, 2009). To better understand the relationship between IPV and alcohol use, Fals-Stewart (2003) collected diaries from 272 men entering either IPV or alcoholism treatment. Participants and their female partners documented alcohol consumption and IPV for 15 months. Men participating in IPV treatment were 8 times more likely and men in alcohol treatment program were 11 times more likely to be physically aggressive toward their partner on days they consumed alcohol. More recently, Wupperman, Amble, Devine, Zonana, Fals-Stewart, and Easton (2009) reported that most female partners of 
men in IPV treatment in their study reported not only being violent with their partners, but also that they were as likely as their partners to use substances the week prior to their partners' participation in IPV treatment. The body of research is clear that IPV and substance abuse are directly related. Fals-Stewart and Kennedy (2005), in fact, argue that the evidence supports a causal relationship between substance abuse and IPV and that substance abuse must be addressed in IPV treatment attempts. Later in this manuscript we discuss research on evidence-based treatment approaches for tco-occurring substance abuse.

\section{Effectiveness of Traditional Treatment}

Accompanying the traditional male-perpetrator/female victim paradigm for understanding IPV in heterosexual relationships was a specific approach to intervention. Men were adjudicated through the court system and mandated to attend all male batterers’ intervention programs (BIPs) while women were offered voluntary victim support services. The BIPs were designed to challenge men's use of male power and teach new, egalitarian ways of relating. Despite the widespread use of this model, a growing body of research has called its efficacy into question.

Treatment of Male offenders

Research into the effectiveness of BIPs has continued since the publication of our last review. In addition to effectiveness studies of individual programs, meta-analyses of the effectiveness research in this area have been published, as well as review articles that have identified the challenges involved in such studies. Two meta-analyses have made important contributions to our knowledge of the outcome of BIP intervention. Babcock, Green and Robie (2004) conducted a meta-analysis of 17 quasi-experimental and 5 experimental studies investigating the treatment effectives of BIPs for partner violent men. Treatment outcome was 
measured in terms of victim report of re-assault and/or police reports of re-assault. For studies measuring recidivism by police report, those with an experimental design had an average treatment effect of $d=0.12$ and those with a quasi-experimental design had an average treatment effect of $d=0.23$, showing a significant but small impact on recidivism for both types of studies. For the studies measuring recidivism by partner report, those with an experimental design had an average treatment effect of $d=0.09$, representing a non-significant impact on recidivism, and those with a quasi-experimental design had an average treatment effect of $d=0.34$, again representing a significant but small impact on recidivism. Babcock et al. also examined differences in treatment effects based on type of treatment, comparing studies using the Duluth model, to Cognitive Behavioral Therapy (CBT) groups, and “other” interventions and found no significant differences in effect sizes based on treatment type. While there is some question about what these small effect sizes actually mean for women who have been assaulted by an intimate partner, Babcock et al. note that, using the most conservative result, the treatment effect based on partner report in experimental studies $(d=0.09)$, treatment is responsible for an approximately one-tenth of standard deviation improvement in recidivism. In other words, a man who is arrested, sanctioned by the court, and treated, has a $40 \%$ chance of remaining nonviolent versus a 35\% chance of remaining non-violent for a man who is arrested and sanctioned but not treated.

Feder and Wilson (2005) also conducted a meta-analysis of BIP outcome studies, using more rigorous inclusion criteria than did Babcock et al (2004), resulting in a sample of 4 experimental and 6 quasi-experimental studies. Again, treatment outcome was measured in terms of partner or police report of re-assault. Based on police reports, the average effect size for experimental studies was $d=0.26$, representing a significant but small effect - a reduction in 
recidivism from $20 \%$ to $13 \%$. Quasi-experimental-designed studies were broken into two groups and analyzed separately. Those comparing men who were mandated to treatment vs. those not mandated to treatment had an average effect size of $d=-0.14$, a non-significant effect. Those comparing men who completed mandated treatment vs. those who were rejected from treatment, who never attended, or who dropped out had an average effect size of $d=0.97$, representing a significant and large treatment effect. However, the authors express reservations about this finding noting that treatment completers may be significantly different from those who are rejected from treatment or who fail to attend or drop out; for instance they may be more highly motivated or more fearful of criminal justice sanctions, and thus the treatment effect may be confounded by these factors. For studies using partner report of re-assault, Feder (2005) report a non-significant average effect size of near zero for experimental studies and a small and negative non-significant average effect size for quasi-experimental studies using a no-treatment control group. Thus this meta-analysis again indicates that treatment effects for BIPs are small to nonexistent, particularly in the stronger studies - those using an experimental design and/or partner reports of re-assault.

While the findings from these two meta-analyses are discouraging, there are a number of challenges in investigating the impact of treatment on re-assault rates that may contribute to the small effect sizes found in these studies (Babcock, et al., 2007; Eckhardt, Murphy, Black, \& Suhr, 2006; Gondolf, 2004). For instance, meta-analyses may still be difficult when the number of available studies, particularly those that utilize an experimental design, is limited. Using an experimental design is also challenging in this field when a "no treatment" control group also often includes monitoring by the criminal justice system, and dropout rates of $40-60 \%$ often mean that the treatment group contains many individuals who either never received treatment or 
received a very low dose. Additionally, while partner reports of re-assault may be preferable to official police reports, given that repeat incidents may not always be reported to the police, outcome studies frequently find very low response rates from partners. The length of follow-up period also presents challenges, as re-assault rates may be higher immediately after completing a program but decline over time, yet maintaining contact with partners for an extended period is problematic. Finally, outcome studies may demonstrate small effect sizes because of challenges inherent in the BIP treatment itself. For instance, court-mandated individuals may not be highly motivated to change, and group treatment approaches, while demonstrating some efficacy for internalizing behaviors, have not been shown to be as effective for externalizing behaviors such as IPV (Babcock, et al., 2007). Additionally, there may be components of the BIPs that are less effective than others for all types of offenders. These challenges have led to another focus within BIP research; efforts to find components or interventions that will increase motivation, reduce dropout, and improve recidivism.

One new area of study has been the application of Motivational Interviewing (MI) interventions (Miller \& Rollnick, 2002) to work with IPV offenders in efforts to increase their engagement with and attendance at group treatment programs. Taft, Murphy, Elliott, and Morrel (2001) investigated the effectiveness of motivational enhancement techniques including telephone calls and handwritten letters to group participants before the commencement of group treatment and immediately following any absences from group. They found significant effects on group attendance compared to a group that did not receive the intervention. Those in the treatment retention group attended roughly $10 \%$ more sessions than did the control group, a small to medium effect size $(d=.35)$. Additionally, only $15 \%$ of men in the treatment retention group dropped out compared to $30 \%$ in the control condition. Finally, there was a significant 
treatment by race interaction effect, with $42 \%$ of minority individuals dropping out of the control group and only $10 \%$ of minority individuals dropping out of the treatment retention group. Effects of attendance on both partner reports of abusive behaviors and criminal justice data of recidivism indicated that higher attendance was associated with less recidivism, lower reported physical assault and injury at post-treatment and lower injury at 6-month follow-up.

While Taft et al. (2001) included their MI intervention throughout the course of BIP treatment; another MI strategy has been to administer brief interventions prior to entry into the BIP group. Results of this approach are mixed. Kristenmacher and Weiss (2008) conducted a randomized controlled trial of a 2-session MI pre-group intervention with 33 men courtmandated to BIP treatment, to determine the effects of a brief MI intervention on offenders’ readiness for change. Those receiving the MI intervention showed a significantly greater pre-topost increase in readiness to change and a significantly greater pre-to-post decrease in external attributions of blame. Similarly, Musser (2008) examined the effectiveness of a 2-session MI pre-group intervention, but with a larger sample and with outcome data that included behavioral variables from in-treatment, post-treatment and 6-month follow-up data. Contrary to Kistenmacher's and Weiss’ findings, Musser et al. found no significant effect of the MI condition on motivation to change prior to group treatment compared to the standard intake procedure (SI) and showed that those in the MI condition were no more likely to begin the group treatment than those in the SI condition. Those in the MI condition did show significantly higher compliance with homework both early and late in treatment, higher therapist ratings of the working alliance late in treatment, and higher rates of outside help-seeking by the end of treatment. Additionally, men in the MI group showed significantly higher assumption of responsibility and endorsement of group value early in treatment, but these effects appeared to 
dissipate by the middle phase of treatment. Although these results indicate some positive effects of the MI intervention on engagement in treatment, outcome data showed no effects on violence based on partner report for the 6 month period following treatment completion.

Effectiveness of treatment for female offenders

Two questions deserve attention in the arena of treatment of female offenders. First, are women's needs in treatment different from men's and second, what is effective treatment? Women's treatment needs have been addressed through the examination of women's motivations to use violence. Stuart, et al. (2006) surveyed 87 women in batterer intervention programs and found the most common reasons given for the use of violence included: to show anger, because her partner provoked violence, self-defense, to show feelings that could not be explained in words, stress, and to get back at a partner or retaliate for emotional hurt. Women who were victims of severe violence were significantly more likely than victims of minor violence to report using violence in self-defense. These findings point to women's use of violence due to problems with emotional regulation, and for reasons of self-defense or retaliation. Using a different research design, Kernsmith (2005) compared male $(n=60)$ and female $(n=54)$ participants in batterer intervention programs and found that motivations for the use of violence differed by gender. Women were more likely than men to report using violence in response to previous abuse, and to get back at or to punish a partner. However, no differences were found between men and women in the use of violence as self-defense. Taken together, these findings suggest that women may use violence to express extreme emotions or in response to stress and that some violence perpetrated by women may occur within the context of mutually violent relationships, where women use violence in order to retaliate, to fight back or, possibly, to defend themselves, 
However, more research is needed to understand whether or not women's use of violence in relationships stems from different motivations than does men’s use of violence.

With the advent of widespread mandatory arrest polices, women are more routinely arrested and mandated to treatment, often within the same or similar programs as those designed for male offenders (Carney \& Buttell, 2004; Dowd, Leisring, \& Rosenbaum, 2005). Because women’s violence may differ from men’s violence and because many batterer intervention programs take a feminist approach that explains violence within a context of male power and control, some have argued that traditional treatment approaches may not be best suited for female offenders (Kernsmith, 2005). Currently no strong experimental studies are available to assess the effectiveness of treatment of female offenders. However, using a single group pre-post design, Carney and Buttell (2004) examined treatment effectiveness for 26 women who had completed a traditional batterer intervention program and found that participants were significantly less passive/aggressive and less likely to use physical violence against their partners than they were before beginning the program. Carney and Buttell further found that at 12 month follow-up only one treatment completer had been rearrested. While these findings may indicate that traditional intervention programs can be effective for female offenders, it is important to note that 55\% of women referred to this treatment program dropped out. Dowd, Leisring and Rosenbaum (2005) examined factors predicting treatment drop out with a sample of 107 domestically-violent heterosexual women. The women participated in a 20 week anger management program that was similar to traditional batterer's intervention but included some adaptations for female participants, including information about mood disorders and PTSD, parenting information, and safety planning. Fifty-eight percent of participants dropped out of the program. Dowd et al. found no differences between drop outs and treatment completers in demographic variables, in 
the history of violence in families of origin, previous relationships, or current relationships, or in past mental health treatment. They did find, however, that women who entered the program voluntarily had fewer pretreatment arrests, were more likely to drop out after intake, and had lower completion rates overall than did court-mandated women. Clearly, as more women are appearing for treatment of IPV, we need to know more both about women's use of violence in intimate relationships and about what constitutes effective intervention for women.

\section{Systemic Treatment of IPV}

Research on the effectiveness of systemic treatment/intervention for IPV is growing but questions remain. In this section of the paper we discuss one major research program (O'Farrell \& Fals-Stewart, 2002), four completed projects, and two projects in the beginning phase of research designed to treat or prevent IPV using systemic interventions. While some of these programs indicate that they are designed to prevent IPV and others to treat IPV, none of these programs are designed to provide primary prevention to the general population. Most of these programs are designed to prevent low-level or situational violence from escalating to more severe violence. Therefore, we review them as a group. The programs reviewed are listed in Table 1. We begin this section, however, with a discussion of screening for IPV in systemic therapies since accurate identification of IPV and risk assessment are the cornerstones of safe and effective treatment.

\section{Insert Table 1 here}

\section{MFTs and Assessment of IPV}

Since many couples choose to remain together after experiencing violence, they often present for family therapy. In fact, studies have demonstrated that between 36 to $58 \%$ of couples who seek regular outpatient treatment have experienced male-to-female physical assault in the 
past year and 37\% to 57\% have experienced female-to-male physical assault (Jose \& O'Leary, 2009). As a result of the high level of IPV in couples coming to therapy, several authors have offered guidelines for universal screening for IPV when working with couples (Bograd, 1999; Stith, et al., 2003). General guidelines suggest screening all couples using individual interviews with both partners, and multimodal assessments (e.g. written questionnaires and verbal interviews). Careful screening and ongoing monitoring are the basis for determining whether conjoint therapy can proceed safely. In fact, assessment of physical violence has been included in the AAMFT Core Competencies recommended for accredited training programs.

Despite this recognition of the need for assessment, there has been very little published research to document how, or if, assessment is being conducted by MFT’s. Todahl, Linville, Chou, and Maher-Cosenza (2008) conducted a qualitative study of MFT interns' experiences of universal screening for IPV with 22 (17 female and 5 male) MFT interns who had an average of 400 client contact hours. All of the interns had participated in an IPV class that addressed universal screening guidelines. Todahl et al. found wide variations in screening practices. Eleven interns reported routine screening while others reported waiting for "red flags” to appear before assessing for violence. Thirteen routinely separated couples to screen for violence while 6 separated couples only rarely, and only 3 interns stated that they used a combination of verbal questions and written questionnaires to assess for violence. In identifying barriers to universal screening, 14 interns expressed concern for victims' safety, fearing that asking about violence would put victims at further risk or re-traumatize them. Others reported that a lack of confidence in their ability to both assess for and treat IPV was a barrier for them.

Schacht, Dimidjian, George and Berns (2009), using a sample of 620 practicing MFTs randomly selected from the AAMFT membership list, found similar variability in assessment 
procedures and limited adherence to universal screening guidelines. Just over half (53.2\%) of participants in this study reported that they screened all couples that they saw the previous year for violence, $42.3 \%$ reported screening some couples, and $4.5 \%$ reported screening no couples. The latter group was excluded from further analysis. Of those who screened for IPV, 37.2\% reported always interviewing partners separately, 54.9\% reported interviewing some partners separately and 7.9\% reported never interviewing partners separately. Finally, 78.9\% reported that they did not use a written self-report instrument during the screening process, and of those who did use a written instrument, only $7.5 \%$ reported using standardized, behaviorally specific questionnaires designed to measure violence. Only 3.5\% of participants reported using all of these procedures described above that constitute appropriate screening for IPV.

In addition, Schacht et al.’s participants varied widely in the criteria they used to determine if conjoint therapy is appropriate when violence is detected. Fifty-two percent reported that they considered the overall prognosis of the relationship, $42 \%$ considered the victim's level of fear and safety in the relationship, 40.5\% considered the severity, frequency, and duration of abuse, 30.2\% considered psychopathology of either victim or perpetrator, and 23.1\% considered whether either the victim or perpetrator was engaged in other therapy services. Of the least endorsed items, only 5.6\% considered the potential effect of couple therapy on current levels of violence, $4.8 \%$ considered injury or lethality of past violence, $1.7 \%$ considered the use or presence of weapons, and $1.4 \%$ considered the perpetrator's history of violence in other relationships. Although based on limited research, it appears that the MFT field falls short of the level of universal screening that has been recommended in the literature. This is a concern given that careful assessment is generally a foundation on which safe use of the systemic models we will describe below is built. 


\section{Behavioral Couples Treatment}

The research group led by O’Farrell and Fals-Stewart has contributed both clinical intervention development and testing as well as more basic research to our understanding and treatment of IPV in couples with concurrent substance abuse disorders. In this paper, we will focus on the outcome studies of their clinical intervention: Behavioral Couples Treatment (BCT).

BCT is a dyadic intervention used to treat adults with substance abuse disorders. The couple is seen conjointly and the non substance abusing partner is enlisted as a support for the substance abusing partner's sobriety. The couple is helped to negotiate a Sobriety Contract which includes a daily Sobriety Trust discussion in which the substance abusing partner reaffirms his or her intent not to use alcohol or drugs that day. The non-substance-abusing partner provides positive support for that intention. Some patients also participate in self-help groups or use medications to support abstinence and take those in the presence of their partner. Discussions, self-help attendance, medication use and relapse are recorded on a calendar by the couple and brought to sessions for further discussion, support of success by the therapist and troubleshooting in cases of relapse. In addition to support for sobriety, BCT also includes skill training modules that increase positive interactions and teach communication skills in the service of managing conflict better. Beginning with small scale pilot studies in the 1970's, the program has grown to include several large, federally-funded randomized controlled clinical trials with a strong body of evidence for the efficacy of BCT in reducing both substance abuse and IPV (FalsStewart, O'Farrell, Birchler, Cordova, \& Kelley, 2005).

BCT began as a successful treatment specifically for alcoholic men and their female partners. In the course of their work on substance abuse, the BCT group began to be interested in the effect of BCT on IPV. There is consistent evidence that both problems co-occur with 
Treatment of Intimate Partner Violence

regularity (see Fals-Stewart, Klostermann, \& Clinton-Sherrod, 2009 for a summary of this literature) and the BCT group began to investigate the impact of BCT on couple violence. FalsStewart et al.(2005) report that, for alcoholic men BCT results in dramatic reductions in IPV after treatment. In two studies (O'Farrell, Murphy, Hoover, Fals-Stewart, \& Murphy, 2004; O'Farrell, Van Hutton, \& Murphy, 1999), the BCT group found that IPV was significantly reduced for male alcoholics following treatment. In the larger 2004 study, the prevalence rate for IPV in a matched nonalcoholic comparison sample was $12 \%$ in the year prior to assessment while $60 \%$ of male alcoholic patients had been violent to their female partners during the same time period. Following treatment, BCT reduced the rate of IPV in the alcoholic sample to $24 \%$ overall - a significant reduction although still higher than the comparison group. Among those men who were no longer drinking, the rate was reduced to $12 \%$-- equal to the nonalcoholic group. Among men who relapsed in the year after treatment, the rate rose to $30 \%$. Thus, for alcoholic men, BCT resulted in reduced violence with the largest reductions being associated with abstinence from alcohol.

Among men abusing substances other than alcohol, Fals-Stewart, Kashdan, O’Farrell and Birchler (2002) found that nearly 50\% of couples reported IPV against a female partner in the year prior to treatment. After treatment, $17 \%$ of couples receiving BCT reported male violence while $42 \%$ of couples in which the male partner participated in an equally intensive individual treatment program reported violence. These findings are based on female partners’ report.

Since their 2005 review paper, the BCT group has continued to investigate the effect of BCT on IPV among substance abusing patients. Schumm, O’Farrell, Murphy, and Fals-Stewart (2009) examined the impact of BCT on partner violence for two years following treatment in a sample of married or cohabiting women who sought treatment for alcoholism with their male 
partners. In the year prior to treatment, both the women and their male partners had higher prevalence and frequency of aggression than did a matched nonalcoholic sample. For couples who received BCT, there were significant decreases in both the first and second year following treatment for both alcohol-abusing women and their male partners on all aggression measures except that male-perpetrated severe violence was not significantly reduced in the first year after BCT. As with male alcoholic patients, abstinence was associated with better violence outcomes. Couples in which the female partner was abstinent were not significantly different from the nonalcoholic sample, except that the male partners of abstinent female participants had greater prevalence and frequency of verbal aggression in the year following treatment compared to those in the matched sample.

In a subsequent study, Fals-Stewart and Clinton-Sherrod (2009) randomly assigned their sample of 207 substance-abusing men and their female partners to either BCT treatment or an individual-based treatment (IBT) for the male substance abusing partner, to determine the impact of participation in BCT on the relationship between substance use and occurrences of IPV. In this version of BCT, the couples' sessions included specific attention to violence prevention and safety. For instance, couples made a verbal agreement not to engage in any angry touching, and if their partners relapsed, women were coached not to engage in any kind of conflict resolution discussion with them. The individual treatment condition (IBT) also included 32 sessions, composed of 1 hour individual-based sessions following a 12-step facilitation model.

In examining differences between groups on substance abuse, there were no differences in percentage of days abstinent (PDA) between those in the BCT or the IBT at pre-treatment or post-treatment. At 12-month follow-up, however, those in the BCT group had significantly higher PDAs than those in the IBT. A similar pattern was seen in rates of violence, with no 
differences between groups at pre- or post-treatment, but at 12-month follow-up those who had received BCT had lower rates of any violence and lower rates of severe violence than those who had received IBT. On days of no substance use, the likelihood of non-severe and severe violence did not differ for those assigned to the BCT or the IBT group. The likelihood of non-severe and severe violence increased significantly on days the man used substances among men who received IBT. However, on days of substance use, the likelihood of IPV was lower for men who had received BCT compared to those receiving IBT. While it is not yet clear what the specific mechanism of action is that gives BCT the advantage in preventing violence on days of drinking, it does appear that BCT fares better than IBT when risk is higher.

Overall, the work of the BCT group has provided strong support for systemic interventions to address substance abuse and also to reduce IPV. Individual treatment of substance abuse did not have nearly the impact on IPV as did systemic treatment. Although this is an encouraging outcome, it must be noted that BCT is typically administered to couples in which only one partner is using substances (Fals-Stewart, O'Farrell, \& Birchler, 2004). Given the high association between substance abuse and IPV for both partners in a couple, this may leave out a significant number of couples seeking treatment.

\section{Domestic Violence Focused Couples Treatment}

Domestic Violence Focused Couples Treatment (DVFCT) was developed beginning in 1997 at Virginia Tech with NIMH funding. Previous publications have described the treatment program (Stith \& McCollum, 2009; Stith, McCollum, Rosen, Locke, \& Goldberg, 2005; Stith, Rosen, McCollum, \& Thomsen, 2004). Couples are carefully screened before beginning DVFCT. A variety of screening criteria are used and clients who are fearful that the treatment 
could lead to increased violence are referred to other treatment options in the community. The 18-week manualized program is based on Solution Focused Brief Therapy (de Shazer, 1985; de Shazer, et al., 2007) and is delivered by co-therapists in two formats - either in multi-couple group (MC) or with an single couple (SC). The goal of DVFCT is to eliminate all forms of violence (psychological, physical, sexual, and stalking), promote self-responsibility, and, if the couple chooses to remain together, enhance the couple relationship.

The program begins with a 6-week therapist- directed separate gender program wherein one co-therapist meets with the male partner in SC or men's group in MC while the other cotherapist meets with the female partner or women's group. This phase of the program has two goals. First, therapists help clients develop a vision of a healthy relationship as a guide for the course of therapy. In addition, this phase also focuses specifically on safety skills that need to be in place before conjoint work begins. This work includes education about IPV, developing safety plans, and learning a negotiated time-out procedure among other things. Also included in the therapist-directed portion of treatment is a motivational enhancement intervention to address the co-occurring problems of substance abuse when appropriate. The conjoint phase of the program includes structural additions to the sessions designed to monitor risk and increase safety. For instance, the co-therapists convene brief separate meetings with the male and female clients at the beginning and end of each session. These sessions are used to confidentially screen for evidence of increased risk and for further occurrences of violence.

In examining the outcome for DVFCT, the project used random assignment to treatment conditions - SC vs MC - and a non-random comparison group. In the current analyses, 83 couples were randomly assigned to either MC or SC treatment. Of these, 55 couples completed the program and the six-month follow-up assessment. Nine couples served as the no-treatment 
comparison group. The analyses examined two broad domains. First, the impact of treatment on physical and psychological violence was examined using the Revised Conflict Tactics Scale (Straus, Hamby, Boney-McCoy, \& Sugarman, 1996). In the second domain, a variety of both relational and individual issues were examined including communication, pursuing and distancing, relationship satisfaction, anger, anxiety and depression.

Results of this research indicate that for both men and women, completing the 18-week program, either SC or MC, led to significant reduction of physical violence toward their partners, as measured by partner reports. However, for men in particular, the multi-couple group seemed to lead to a host of other benefits not seen in single couple condition (see Figure 1). For women, the pattern is less clear with a mix of benefits spread between the two formats. The DVFCT developers are continuing to develop the program and conduct research on the effect of the program. Studies examining the differential effect of the multi-couple group vs. the single couple condition are ongoing.

Insert Figure 1 here

Couples Abuse Prevention Program

LaTaillade and colleagues (LaTaillade, Epstein, \& Werlinich, 2006) developed the Couples Abuse Prevention Program (CAPP), a cognitive-behavioral couple treatment that seeks to address the risk factors for IPV in couples with a history of minor-to-moderate physical and/or psychological aggression. In attending to risk factors such as negative attributions and communication and problem-solving deficits, CAPP aims to improve relationship satisfaction 
and lower the risk for future incidents of violence. The treatment protocol begins with a multimodal assessment of individual and couple functioning and an assessment of prevalence and frequency of psychological and physical aggression. Conjoint therapy is determined to be appropriate if the level of physical violence is low-to-moderate (not resulting in injury) and neither partner is perceived to be in imminent danger of physical harm. In addition, both partners must acknowledge that abuse is a problem, be willing to work toward an abuse-free relationship, be committed to staying together, and feel safe participating in conjoint treatment.

The CAPP treatment protocol has been pilot tested in comparison to Treatment as Usual (TU) at a the University of Maryland family and couple therapy clinic (LaTaillade, et al., 2006). In this pilot study, couples who met the inclusion criteria and consented to participate in the study (47.5\% of those who were eligible) were randomly assigned to CAPP ( $n=17$ couples) or TU ( $n=21$ couples). The TU condition was comprised of individual couple therapy based on a variety of systems-informed therapy models, depending upon the framework used by the therapist assigned to the case. Treatment in the CAPP condition followed a structured format with each session focused on a particular content area. In both treatment conditions, couples attended ten 90-minute sessions, clients were asked to sign no-violence contracts and treatment was focused on reducing systemic patterns that lead to IPV.

In the CAPP condition, first session included an overview of the program and discussion of the relationship history, completion of a no-violence contract and identification of a written set of goals for therapy, with an understanding that the primary goal of CAPP is for the couple to have an abuse-free relationship. For homework, couples were asked to review their goals, revise them if they wish, and bring them to the following session. In the second session co-therapists refined treatment goals, educated partners about cognitive-behavior constructs, taught strategies 
for anger management, and provided education about the consequences of constructive versus destructive forms of communication. For homework, partners were asked to practice the anger management strategies. In sessions 3 and 4 therapists taught expressive and listening skills, and had partners practice these skills in session and for homework, along with practicing anger management skills for homework. Sessions 5 through 7 provided instruction and practice skills for resolving conflict without abuse, and partners were coached in combining communication and problem-solving skills. Finally, in sessions 8 through 10, the communication and problemsolving skills were supplemented with relationship recovery and enhancement strategies to increase the proportion of positive activities and sharing, develop greater mutual support, increase affection and intimacy, and increase partners’ ability to work as a team in setting and working towards goals. Additionally in session 10, therapists summarized the couple's progress toward their initial treatment goals and addressed relapse prevention through the identification of skills that had been learned and ways to maintain progress that had been achieved.

Research on CAPP found largely similar outcomes compared to TU. Relationship satisfaction is increased and psychological aggression decreased on at least some measures in both conditions while there were no differences in physical aggression likely due to the low frequency of physical aggression in the sample to begin with. Based on coded communication measures, CAPP produced less negative communication for both males and females while there were no such changes in TU. Men in the CAPP condition trended toward more positive communication while there were no changes in positive communication in TU.

Circles of Peace

Beginning with principles of restorative justice, Mills (2008) developed a systemic intervention called Circles of Peace (CP) as an alternative to traditional BIP treatment. Circles of 
Peace involves conferences between victims and offenders that also include roles for family members and friends that provide support and care to each individual involved in a crime (Grauwiler, 2004), A CP is made up of a Circle Keeper, typically a community member trained in working with IPV, the offender (termed “the applicant”), and the victim (“the participant”), if she/he chooses to participate. In addition, extended family members, friends, and/or community members may become involved to support the individuals, and one person is designated as the “safety monitor”, who monitors the family between conferences. A CP involves the use of an intake assessment that includes a safety screening to ensure that it is safe for the victim to participate and an "Initial Social Compact”, a document signed by the offender promising not to be violent and to participate in any other treatments that might be necessary. Circles further involve the use of a "talking piece", an object identified by the family which must held by the speaker when talking, and begin with the rules of no violence, no blaming, and a focus on acknowledgement, understanding, responsibility, and healing.

Mills received funding from the National Science Foundation to study the effectiveness of CP compared to a traditional BIP treatment in Nogales, Arizona. In this study, 152 court adjudicated cases were randomly assigned to CP or BIP, and recidivism data in the form of subsequent arrest records were obtained for 24 months following treatment for all those assigned to either treatment, whether or not they completed treatment. Groups were comparable at baseline, and over half of the CP offenders had victims who agreed to participate in the CP program. Preliminary results, which have not yet been published (Mills, 2009), indicate that CP offenders had significantly fewer subsequent overall arrests in the 24 months following treatment than did BIP offenders, including fewer arrests for IPV; however the differences between groups in subsequent IPV arrests were not statistically significant. Mills and her research team are 
currently in the process of conducting a follow-up study that will include a larger sample size and two phases of research, the first comprised of a comparison between BIP treatment and BIP plus CP treatment, and the second comprised of a comparison between BIP, BIP plus CP, and BIP plus a couple’s treatment program based on a Couples Conflict Group.

Motivational Interviewing

Woodin \& O’Leary (In Press) have reported on the effectiveness of a targeted brief motivational interviewing (MI; Miller \& Rollnick, 2002) intervention to prevent IPV in high risk heterosexual dating couples. In this study, 50 college students and their partners underwent a 2 hour assessment session and then were randomly assigned to receive either the MI feedback condition or the minimal feedback condition. Couples had to have been dating for at least 3 months, with no history of marriage or cohabitation and at least one act of male-to-female physical aggression reported by either partner on the Revised Conflict Tactics Scale (CTS2; (Straus, et al., 1996)). At the assessment session, partners independently filled out questionnaires assessing partner aggression, problem alcohol use, acceptance of partner aggression, relationship satisfaction and commitment, and levels of depression and anxiety. Questionnaires were revised where applicable to report only on the last 3 months, in order to maintain consistency with the three month follow-up periods. Couples then jointly completed a semi-structured Oral History Interview (OHI; (Buehlman, Gottman, \& Katz, 1992) regarding the history and course of their relationship, with no questions addressing partner aggression.

Couples were then randomly assigned to feedback conditions. In the MI feedback condition partners met individually with a therapist who provided them with a two-page individualized feedback sheet regarding their self-reported levels of aggression, as well as risk factors including psychological aggression and alcohol use, and consequences of aggression such 
as depression, anxiety and relationship distress. Therapists provided feedback in an empathic and non-confrontational way, consistent with training in MI interventions and protocols from a standardized treatment manual. Participants were asked to respond to the feedback and therapists reinforced any statements indicating motivation to change. Each feedback session was no more than 45 minutes, the order in which partners received feedback was randomly assigned by gender, and for safety reasons feedback was given without reference to the partner's report. Finally, therapists met with the couple together for 15 minutes, again not sharing any individual feedback, but instead discussing the couples’ overall hopes and concerns for their relationship, with the therapist again reinforcing any statements regarding motivation to change any risk factors for aggression.

In the minimal feedback condition each partner received a 10 minute individualized feedback session including written feedback concerning their overall relationship adjustment on the Dyadic Adjustment Scale (DAS; (Spanier, 1976)) and verbal definitions of the components of relationship adjustment. General factors that may impact adjustment were briefly discussed and any questions raised by participants were answered.

Follow-up questionnaires with regard to partner aggression, problem alcohol use, acceptance of partner aggression, relationship satisfaction and commitment, and levels of depression and anxiety were administered online at 3, 6, and 9 months after the intervention. Results showed a significant overall reduction in physical aggression perpetration over time (effect size $d=0.58$ ), and a moderate-sized treatment effect for both men and women as participants in the MI group reduced their physical aggression at a significantly greater rate than those in the minimal feedback condition $(d=0.56)$. Additionally, both men and women in the MI group were more likely to report a reduction in problem drinking compared to those in the 
minimal feedback group $(d=0.70)$, with no significant interaction between gender and feedback condition.

\section{Summary of Completed Systemic Projects}

It is clear from these studies that it is possible to treat IPV in heterosexual couples using systemic interventions. Completed studies range from a one-session motivational intervention for college student dating couples, conducted by Woodin and O'Leary, to a multi-modal project involving conjoint treatment in addition to self-help attendance and individual treatment, conducted by O’Farrell and Fals-Stewart, to multi-couple or single couple treatment designed especially to address IPV, conducted by Stith and colleagues and LaTaillade and colleagues, to a restorative justice approach, which includes, not only the couple involved in the IPV, but relevant support systems. In each of these completed projects, the systemic interventions decreased IPV and risk-factors for IPV with no increase in risk. As a result of these earlier studies, the U.S. federal government has shown increasing interest in funding randomized control trials of systemic interventions to prevent IPV. We are aware of two such projects currently in progress.

Couples Together Against Violence (CTAV) (Bradley, Friend, \& Gottman, 2009) is based on Gottman’s (Gottman, 1994; Gottman \& Silver, 1999; Jacobson \& Gottman, 1998) three decades of work with over 3000 couples, and is designed specifically to address a variety of outcomes including low level situational violence in low-income couples. The project is funded by the Administration for Children and Families of the U. S. Department of Health and Human Services. The CTAV intervention sessions take a solution-focused and strengths-based approach, emphasizing skills for constructive conflict management, creating and maintaining emotional intimacy, coping with stress and depression, and including information about the 
Treatment of Intimate Partner Violence

importance of fathers and healthy marriage. The 22 sessions address 5 content areas: Managing Conflict; Managing Stress; Fathers, Marriage, and Parenting; Creating Shared Meaning; and Maintaining Intimacy. Importantly, the project plans to look not only at outcome but at the mechanisms specifically responsible for any observed decrease in IPV. Preliminary results from data collected before the program began and at post-test with 115 couples indicated that the program was successful in strengthening relationships and decreasing conflict (Bradley, Friend, \& Gottman, unpublished), however no significant differences in levels of violence between treatment and control groups or between pre and post-tests for the treatment group were found in the preliminary analyses (Bradley,2010). The research team will be continuing to collect analyze follow-up data at six months and twelve months following completion of the program.

In a project funded by the Centers for Disease Control, Heyman and Slep are evaluating Couple Care for Parents (CCP), an intervention for new parents under age 30 aimed at preventing the development or escalation of IPV. The intervention was originally developed and tested in Australia. Modified for a North American clientele and augmented with material to specifically address IPV, CCP is a psychoeducational intervention aimed at decreasing stress, improving communication and parenting skills, and maintaining couple intimacy after the birth of a child. In a randomized controlled trial testing Couple CARE for Parents, males and females with a newborn were assessed shortly after the baby was born, and randomly assigned to either the Couple CARE for Parents of Newborns program, or a wait-list control that would get Couple CARE for Parents of Toddlers after the 24-month assessments were over. Preliminary analyses indicate that while males in the control group report significant increases from birth to 8 months in the amount of physical and psychological aggression they receive from their partners, men in the treatment group show no significant increases. Furthermore, males in the treatment group 
Treatment of Intimate Partner Violence

show significant decreases in received aggression from birth to 15 months. Preliminary analyses also indicate that females in the control group report significant decreases in relationship satisfaction from birth to 8 months, but females in the treatment group report no significant change in satisfaction. However, women in both groups did not see a change in received physical or psychological aggression (D. Mitnick, personal communication, December 23, 2010). Follow-up data collection is ongoing.

\section{Limitations of the Research to Date}

Despite the encouraging findings from extant studies of systemic interventions, as well as the fact that funded projects are in process, issues still remain that need to be addressed. No work, to date, has addressed the processes involved in changing violent relationships although the Gottman project plans to do so. Thus, we do not know what aspects of these interventions lead to change and what aspects of these interventions may be unnecessary. Researchers have made efforts to assess fidelity to treatment within their protocols, however, little of this work has been published. While one of the concerns expressed by those who deliver batterer intervention programs is that conjoint treatment approaches are more expensive than male-only approaches, no research has been conducted on the cost-effectiveness of systemic treatment approaches, especially in comparison to batterer intervention approaches. We also do not know much about for whom these interventions are most effective and/or for whom they might be ineffective or even dangerous. Most current projects have fairly stringent exclusion criteria and do not allow highly violent couples or couples in which intimate terrorism is occurring to participate in the treatment. In addition to a lack of diversity in types of violence, the research to date has not evaluated the use of systemic interventions with clients from diverse cultural backgrounds, nor have researchers examined their use with same-sex couples. Furthermore, we lack effectiveness 
research studies to examine the use of systemic interventions in "real world settings". We need future research which addresses factors leading to change, which more clearly examines who does and does not change as a result of these interventions, and research in settings more likely to represent the settings in which most clinicians practice.

Another issue deserving attention is the widening gap between research and practice when it comes to systemic interventions. Despite evidence that systemic interventions can be useful in deceasing violence and improving couple relationships, the standard clinical practice continues to be separate gender group interventions for perpetrators using pro-feminist or cognitive-behavioral approaches (Saunders, 2008). Regardless of the studies calling the effectiveness of separate gender intervention into question, these programs are institutionalized in state standards for IPV intervention across the country. Forty-five states currently have standards for IPV intervention and, of those, 95\% mandate a curriculum based on power and control with or without attention to social psychological issues such as skill deficits and faulty modeling in the perpetrator's family of origin (Maiuro \& Eberle, 2008). More to the point, 68\% of state standards explicitly prohibit conjoint couples’ treatment during the primary phase of IPV intervention while the remaining 32\% remain silent on the issue or limit the circumstance in which couples’ sessions can be held. Not only do such standards limit the ability of couples to access a treatment that can be helpful to them if they remain together in the wake of violent acts - or if they want to separate safely yet co-parent their children - they also pose difficulties for researchers who wish to test conjoint approaches in community agencies with the populations to which they are likely to be delivered.

The existence of state standards that prohibit the use of systemic interventions may also contribute to the lack of research that is accretive in this field. Other than the work conducted by 
Fals-Stewart and colleagues (which is conducted within substance abuse programs), there are no programs of research studies in this area that build on each other, nor have researchers other than the model developers themselves been involved in evaluating systemic interventions. Furthermore, while state standards may place constraints around the types of intervention programs that may be used for arrested offenders, funding limitations also exist in this area, as the focus of much federal funding has narrowed to the two areas of DSM diagnoses and prevention programs.

\section{Conclusion}

Intimate partner violence continues to be a significant social problem with major gaps in our understanding of how best to intervene, including understanding which specific factors contribute to reductions in physical aggression for different types of perpetrators. Current accepted treatments appear not to be living up to the promise they once held and newer approaches remain controversial and often rejected by those on the frontlines. As a violent crime occurring in an attachment relationship, IPV garners the attention of social institutions with widely divergent approaches. The judicial system’s reliance on sanction and rehabilitation collides with the mental health system's approach of understanding and reconciliation, for instance. It is also difficult to know how to categorize these acts when we see severely injured victims unwilling to leave their abusers or couples who declare unequivocally their love for one another yet psychologically attack each other in extreme ways. Systemic therapists have much to contribute to how society addresses IPV but we cannot do this work in isolation. We must remain part of a coordinated community approach. Perhaps the promising treatments we are writing about 10 years from now will include models that integrate what, at this point, remain opposing viewpoints. 


\section{A Clinician Responds}

The authors provided a detailed review of the current state of the relationship violence literature that suggests a number of important clinical implications. Despite increased research and clinical attention, researchers continue to report that intimate partner violence (IPV) occurs in an alarming number of relationships. In clinical populations, the rates of IPV may approach 50\% (O'Leary, Vivian, \& Malone, 1992). The clear implication is that all Marriage and Family Therapists will work with couples and families that are affected by violence. Therefore, it is essential that MFT’s posses basic knowledge about assessment and intervention with IPV. Perhaps the most significant implication of the study findings presented in the literature review is that clinicians must reevaluate traditionally accepted schemas about relationship violence.

The research suggests that clinicians should expand on the traditional models of relationship violence characterized by a controlling male perpetrator and a female victim. Instead, clinicians should be open to the fact that both men and women use violence in relationships and both men and women suffer as a result. Additionally, research based typologies of violence require that clinicians be attuned to the reality that there is no archetypal perpetrator of violence or violent relationship. Instead, violence in intimate relationships takes many forms (Johnson \& Ferraro, 2000) and clinicians are cautioned not to overlook violence that does not conform to traditional expectations. The generally less than optimal outcomes reported in the research literature for batterer intervention programs are probably less a function of the quality of the interventions and more a function of attempting to treat all relationship violence using the same model.

Traditional "best practices" for intervention with relationship violence have focused on ending men's use of violence toward women and addressing power imbalances anchored in the 
patriarchal nature of larger social structures. While challenging social injustice that contributes to relationship violence remains a vitally important subject for research, public policy initiatives, and clinical intervention, it is clear that effective clinical interventions for relationship violence must also include interventions designed to address types of violence that do not fit the traditional narrative. In addition, it is necessary to examine whether traditional methods of service delivery are appropriate for systemic intervention with IPV. A single therapist meeting with clients for a 50 minute hour in an office setting may not be ideal. Instead, creative interventions for IPV employ a variety of methods including, but not limited to, group therapy, extended sessions, co-therapy teams, and combinations of service delivery formats.

The good news for MFT's is that research supports the efficacy of systemic interventions for IPV. Marriage and family therapy training provides an essential foundation for assessment and intervention at the level of the relationship. However, systemic intervention with IPV presents significant challenges for clinicians. Systemic interventions for IPV are often resource intensive and many clinicians may find they are unable to implement research based interventions due to the restrictions of their practice setting. It is unclear whether some research based interventions can remain effective while being adapted for use in private practice or community mental health settings. As a result, clinicians should actively evaluate whether they are the best resource for intervention with IPV and be familiar with the resources available in their community.

The recognition that IPV takes many forms requires that clinicians become increasingly skilled at assessing for multiple types of violence. Unfortunately, the research suggests that clinicians do a poor job of screening for IPV (Harway \& Hansen, 1993) and lack confidence in their ability to work effectively with IPV (Todahl, et al., 2008). Practicing in accordance with 
recommendations for universal screening requires that clinicians have specific training related to IPV and employ violence specific standardized assessments (Bograd, 1999; Stith, et al., 2003). While some therapists are fortunate to have received IPV specific training in academic training programs or from clinical supervisors, many will have to seek out additional training in the face of the reality that any therapist working with couples or families will eventually be working with IPV. The recommendations for universal screening also highlight the need for the development of additional violence specific assessments for use by clinicians.

Despite the promise shown by systemic interventions for IPV and even with IPV specific training, systemic intervention with relationship violence carries with it inherent risks. It is unfortunate that so few clinicians were found to consider the potential safety implications of couple therapy when IPV is an issue (Schacht, 2009). Safety must be the primary consideration with any intervention for IPV and systemic interventions increases the complexity involved in evaluating and maintaining client safety. At the same time, there exists a compelling argument that the best way to promote client safety is to eliminate violence in their relationships. If research continues to support the efficacy of systemic interventions for IPV, clinicians would benefit greatly from process research that identifies exactly what elements of treatment programs are safe and effective.

Research and clinical intervention with IPV has long produced a contradiction for the field of Marriage and Family Therapy. A systemic perspective is the common thread that unites the profession. However, perhaps in response to legitimate concerns raised by the feminist critique of family therapy, the field has resisted the application of systemic concepts to clinical intervention with IPV. It is encouraging that emerging research is providing support for a more systemic conceptualization of IPV and support for systemic intervention with IPV. As we move 
Treatment of Intimate Partner Violence

forward, the interests of our clients will be best served by developing efficacious interventions

for IPV that focus on eliminating relationship violence while honoring the lessons from our past by attending to issues of power and safety. 


\section{References}

Afifi, T. O., MacMillan, H., Cox, B. J., Asmundson, G. J. G., Stein, M. B., \& Sareen, J. (2009). Mental health correlates of intimate partner violence in marital relationships in a nationally representative sample of males and females. Journal of Interpersonal Violence, 24(8), 1398-1417.

Anderson, K. L. (2004). Perpetrator or victim? Relationships between intimate partner violence and well-being. Journal of Marriage and Family, 64(2), 851-863.

Archer, J. (2000). Sex differences in aggression between heterosexual partners: A meta-analytic review. Psychological Bulletin, 126(5), 651-680.

Babcock, J. C. (2003). Toward a typology of abusive women: Differences between partner-only and generally violent women in the use of violence. Psychology of Women Quarterly, 27(2), 153.

Babcock, J. C., Canady, B. E., Graham, K., \& Schart, L. (2007). The evolution of battering interventions: From the dark ages into the scientific ages. In J. Hamel \& T. L. Nicholls (Eds.), Family Interventions in Domestic Violence: A Handbook of Gender-Inclusive Theory and Treatment (pp. 215-244). New York: Springer Publishing Company.

Babcock, J. C., Costa, D. M., Green, C. E., \& Eckhardt, C. I. (2004). What situations induce intimate partner violence? A reliability and validity study of the Proximal Antecedents to Violent Episodes (PAVE) scale. J Fam Psychol, 18(3), 433-442.

Babcock, J. C., Green, C. E., \& Robie, C. (2004). Does batterers' treatment work? A metaanalytic review of domestic violence treatment. Clin Psychol Rev, 23(8), 1023-1053. 
Treatment of Intimate Partner Violence

Bograd, M. (1999). Battering and couples therapy: Universal screening and selection of treatment modality. Journal of marital and family therapy, 25(3), 291.

Bradley, R., Friend, D., \& Gottman, J. (2009). Couples Together Against Violence.

Bradley, R., Friend, D., \& Gottman, J. (unpublished). Creating healthy relationships in lowincome, distressed couples: Reducing conflict and encouraging relationship skills and satisfaction. Bradley, R. (November 2010). Personal Communication.

Buehlman, K. T., Gottman, J. M., \& Katz, L. F. (1992). How a couple views their past predicts their future: Predicting divorce from an oral history interview. Journal of Family Psychology.Special Issue: Diversity in contemporary family psychology, 5(3-4), 295-318.

Carney, M. M., \& Buttell, F. P. (2004). A multidimensional evaluation of a treatment program for female batterers: A pilot study. Research on Social Work Practice, 14(4), 249-258. de Shazer, S. (1985). Keys to Solution in Brief Therapy. New York: Norton.

de Shazer, S., Dolan, Y., Korman, H., Trepper, T., McCollum, E. E., \& Berg, I. K. (2007). More than Miracles: The State of the Art of Solution-Focused Brief Therapy. Binghamton, NY: Haworth.

Dowd, L., Leisring, P. A., \& Rosenbaum, A. (2005). Partner aggressive women: Characteristics and treatment attrition. Violence and victims, 20(2), 219.

Eckhardt, C., Murphy, C., Black, D., \& Suhr, L. (2006). Public Health Reports, 121, 369-381.

Fals-Stewart, W. (2003). The occurrence of partner physical aggression on days of alcohol consumption: a longitudinal diary study. Journal of consulting and clinical psychology, 71(1), 41. 
Treatment of Intimate Partner Violence

Fals-Stewart, W., \& Clinton-Sherrod, M. (2009). Treating intimate partner violence among substance-abusing dyads: The effect of couples therapy. Professional Psychology: Research and Practice, 40(3), 257-263.

Fals-Stewart, W., Kashdan, T. B., O'Farrell, T. J., \& Birchler, G. R. (2002). Behavioral couples therapy for drug-abusing patients: effects on partner violence. J Subst Abuse Treat, 22(2), 87-96.

Fals-Stewart, W., \& Kennedy, C. (2005). Addressing intimate partner violence in substanceabuse treatment. Journal of substance abuse treatment, 29(1), 5.

Fals-Stewart, W., Klostermann, K., \& Clinton-Sherrod, M. (2009). Substance abuse and intimate partner violence. In K. D. O’Leary \& E. M. Woodin (Eds.), Psychological and physical aggression in couples: causes and interventions (pp. 251-269). Washington, D.C.: American Psychological Association.

Fals-Stewart, W., Klostermann, K., Yates, B., O'Farrell, T., \& Birchler, G. (2005). Brief relationship therapy for alcoholism: a randomized clinical trial examining clinical efficacy and cost-effectiveness. Psychology of addictive behaviors, 19(4), 363.

Fals-Stewart, W., O'Farrell, T., Birchler, G., Cordova, J., \& Kelley, M. (2005). Behavioral couples therapy for alcoholism and drug abuse: Where we've been, where we are and where we're going. Journal of Cognitive Psychotherapy, 19, 229-246.

Fals-Stewart, W., O'Farrell, T. J., \& Birchler, G. R. (2004). Behavioral couples therapy for substance abuse: rationale, methods, and findings. Sci Pract Perspect, 2(2), 30-41.

Feder, L. (2005). A meta-analytic review of court-mandated batterer intervention programs: Can courts affect abusers' behavior? Journal of experimental criminology, 1(2), 239. 
Gondolf, E. (2004). Evaluating batterer counseling programs: A difficult task showing some effects and implications. Aggression and violent behavior, 9(6), 605.

Gottman, J. (1994). Why Marriages Succeed or Fail. New York: Simon and Schuster.

Gottman, J., \& Silver, N. (1999). The Seven Principles for Making Marriage Work. New York: Crown Publishing.

Grauwiler, P. (2004). Moving beyond the criminal justice paradigm: A radical restorative justice approach to intimate abuse. Journal of sociology and social welfare, 31(1), 49.

Harway, M., \& Hansen, M. (1993). Therapist perceptions of family violence. In M. Harway \& M. Hansen (Eds.), Battering and family therapy:

A feminist perspective (pp. 42-53). Newbury Park, CA: Sage.

Jacobson, N., \& Gottman, J. (1998). When Men Batter Women: New Insights into Ending Abusive Relationships: Simon and Schuster.

Johnson, M. P. (2006). Conflict and control: Gender symmetry and asymmetry in domestic violence. Violence Against Women, 12, 1003-1018.

Johnson, M. P., \& Ferraro, K. J. (2000). Research on domestic violence in the 1990s: Making distinctions. Journal of Marriage and the Family, 62, 948-963.

Jose, A., \& O'Leary, K. D. (2009). Prevalence of partner aggression in representative and clinic samples. In K. D. O'Leary \& E. M. Woodin (Eds.), Psychological and physical aggression in couples: causes and interventions (pp. 15-35). Washington, D.C.: American Psychological Assoication.

Justice, U. S. D. o. (1998). Alcohol and crime: An analysis of national data on the prevalence of alcohol involvement in crime. Washington, DC: Bureau of Justice Statistics. 
Treatment of Intimate Partner Violence

Kernsmith, P. (2005). Exerting power or striking back: A gendered comparison of motivations for domestic violence perpetration. Violence and victims, 20(2), 173-185.

Kistenmacher, B., \& Weiss, R. L. (2008). Motivational interviewing as a mechanism for change in men who batter: A randomized controlled trial. Violence and victims, 23(5), 558.

LaTaillade, J., Epstein, N. B., \& Werlinich, C. A. (2006). Conjoint treatment of intimate partner violence: A cognitive behavioral approach. Journal of Cognitive Psychotherapy, 20(4), 393.

Maiuro, R. D., \& Eberle, J. A. (2008). State standards for domestic violence perpetrator treatment: Current status, trends, and recommendations. Violence and Victims, 23.

Miller, W. R., \& Rollnick, S. (2002). Motivational interviewing: Preparing people for change (2nd ed.). New York: Guilford Press.

Mills, L. G. (2008). Violent Partners: A Breakthrough Plan for Ending the Cycle of Abuse. New York, NY: Basic Books.

Musser, P. (2008). Motivational interviewing as a pregroup intervention for partner-violent men. Violence and victims, 23(5), 539.

O'Farrell, T. J., \& Fals-Stewart, W. (2002). Behavioral couples and family therapy for substance abusers. Curr Psychiatry Rep, 4(5), 371-376.

O'Farrell, T. J., Murphy, C. M., Hoover, S. A., Fals-Stewart, W., \& Murphy, M. (2004). Domestic violence before and after couples-based alcoholism treatment: The role of treatment involvement and abstinence. Journal of Clinical and Consulting Psychology, 72, 202-217.

O'Farrell, T. J., Van Hutton, V., \& Murphy, C. M. (1999). Domestic violence before and after alcoholism treatment: a two-year longitudinal study. J Stud Alcohol, 60(3), 317-321. 
Treatment of Intimate Partner Violence

O'Leary, K. D., Vivian, D., \& Malone, J. (1992). Assessment of physical aggression against women in marriage: The need for multimodal assessment. Behavioral Assessment, 14, 514.

Saunders, D. G. (2008). Group interventions for men who batter: a summary of program descriptions and research. Violence Vict, 23(2), 156-172.

Schacht, R. (2009). Domestic violence assessment procedures among couple therapists. Journal of marital and family therapy, 35(1), 47.

Schumm, J., O'Farrell, T., Murphy, C., \& Fals-Stewart, W. (2009). Partner violence before and after couples-based alcoholism treatment for female alcoholic patients. Journal of consulting and clinical psychology, 77(6), 1136.

Simpson, L. E., Doss, B. D., Wheeler, J., \& Christensen, A. (2007). Relationship violence among couples seeking therapy: Common couple violence or battering? Journal of Marital \& Family Therapy, 33(2), 270-283.

Smith Stover, C., Meadows, A. L., \& Kaufman, J. (2009). Interventions for intimate partner violence: Review and implications for evidence-based practice. Professional Psychology: Research and Practice, 40, 223-233.

Spanier, G. (1976). Measuring dyadic adjustment: New scales for assessing the quality of marriage and similar dyads. Journal of Marriage and Family, 38(1), 15.

Stith, S. M., \& McCollum, E. E. (2009). Couples treatment for physical and psychological aggression. In D. K. O’Leary \& E. M. Woodin (Eds.), Understanding Psychological and Physical Aggression in Couples: Existing Evidence and Clinical Implications. Washington, DC: American Psychological Association. 
Treatment of Intimate Partner Violence

Stith, S. M., McCollum, E. E., Rosen, K. H., Locke, L., \& Goldberg, P. M. (2005). Domestic violence focused couples treatment. In J. Lebow (Ed.), Handbook of Clinical Family Therapy. New York: John Wiley.

Stith, S. M., Rosen, K. H., \& McCollum, E. E. (2003). Effectiveness of couples treatment for spouse abuse. Journal of Marital and Family Therapy, 29, 407-426.

Stith, S. M., Rosen, K. H., McCollum, E. E., \& Thomsen, C. J. (2004). Treating intimate partner violence within intact couple relationships: Outcomes of multi-couple versus individual couple therapy. Journal of Marital and Family Therapy, 30(3), 305-318.

Straus, M., Hamby, S., Boney-McCoy, S., \& Sugarman, D. (1996). The revised Conflict Tactics Scales (CTS2): Development and preliminary psychometric data. Journal of Family Issues, 17(3), 283-316.

Stuart, G. L., Moore, T. M., Gordon, K. C., Hellmuth, J. C., Ramsey, S. E., \& Kahler, C. W. (2006). Reasons for intimate partner violence perpetration among arrested women. Violence Against Women, 12(7), 609-621.

Swan, S. (2002). A typology of women's use of violence in intimate relationships. Violence Against Women, 8(3), 286.

Taft, C. T., Murphy, C. M., Elliott, J. D., \& Morrel, T. M. (2001). Attendance-enhancing procedures in group counseling for domestic abusers. Journal of Counseling Psychology, 48(1), 51-60.

Tjaden, P. (2000). Prevalence and consequences of male-to-female and female-to-male intimate partner violence as measured by the National Violence Against Women Survey. Violence Against Women, 6(2), 142. 
Todahl, J. L., Linville, D., Chou, L.-Y., \& Maher-Cosenza, P. (2008). A qualitative study of intimate partner violence universal screening by family therapy interns: Implications for practice, research, training, and supervision. Journal of Marital \& Family Therapy, 34(1), 28-43.

Whitaker, D. J., Haileyesus, T., Swahn, M., \& Saltzman, L. S. (2007). Differences in frequency of violence and reported injury between relationships with reciprocal and nonreciprocal intimate partner violence. American Journal of Public Health, 97(5), 941-947.

White, H. R., \& Chen, P. (2002). Problem drinking and intimate partner violence. Journal of Studies on Alcohol, 63(2), 205-214.

Woodin, E., \& O'Leary, K. D. (In Press). Motivational interviewing as a targeted prevention approach for physically aggressive dating couples. Prevention Science.

Wupperman, P., Amble, P., Devine, S., Zonana, H., Fals-Stewart, W., \& Easton, C. (2009). Violence and substance use among female partners of men in treatment for intimatepartner violence. Journal of the American Academy of Psychiatry and the Law, 37(1), 7581. 
Treatment of Intimate Partner Violence

Figure 1: DVFCT Significant Changes for Males and Females

\begin{tabular}{|l|c|c|c|}
\hline & $\begin{array}{c}\text { Single } \\
\text { Couple }\end{array}$ & $\begin{array}{c}\text { Multi- } \\
\text { Couple } \\
\text { Group }\end{array}$ & \\
& $\mathrm{N}=17$ & $\mathrm{~N}=28$ & $\mathrm{~N}=9$ \\
\hline Physical Aggression (Partner report) & $\mathrm{M} \quad \mathrm{F}$ & $\mathrm{M} \quad \mathrm{F}$ & \\
\hline Psychological Aggression (Partner & $\mathrm{M}$ & $\mathrm{M} \quad \mathrm{F}$ & \\
report) & & & \\
\hline Marital Conflict & & $\mathrm{M} \quad \mathrm{F}$ & \\
\hline Marital Satisfaction & $\mathrm{F}$ & $\mathrm{M} \quad \mathrm{F}$ & \\
\hline Constructive Communication & $\mathrm{F}$ & $\mathrm{M} \quad \mathrm{F}$ & \\
\hline Destructive Communication & & $\mathrm{M}$ & \\
\hline Partner Pursues, Respondent Distances & $\mathrm{F}$ & $\mathrm{M}$ & \\
\hline Respondent Pursues, Partner Distances & & $\mathrm{M}$ & \\
\hline Anger & & $\mathrm{M}$ & \\
\hline Anxiety & & $\mathrm{M}$ & \\
\hline Respondent Differentiation & & $\mathrm{F}$ & \\
\hline Partner Differentiation & & & \\
\hline
\end{tabular}

$\mathrm{M}=$ Males

$\mathrm{F}=$ Females 


\begin{tabular}{|c|c|c|c|c|c|}
\hline \multicolumn{6}{|c|}{$\begin{array}{c}\text { Table 1: Couples Treatment for Domestic Violence } \\
\text { EXPERIMENTAL DESIGN }\end{array}$} \\
\hline $\begin{array}{l}\text { Author/Year/ } \\
\text { Name of } \\
\text { Program }\end{array}$ & Comparison Conditions & $\begin{array}{l}\text { Sample } \\
\text { Size }\end{array}$ & Outcome & $\begin{array}{l}\text { Outcome } \\
\text { Measure }\end{array}$ & $\begin{array}{l}\text { Follow- } \\
\text { up } \\
\text { Period }\end{array}$ \\
\hline $\begin{array}{l}\text { LaTaillade, } \\
\text { Epstein, \& } \\
\text { Werlinch, } 2006 \\
\text { Couples Abuse } \\
\text { Prevention } \\
\text { Program }\end{array}$ & $\begin{array}{l}10 \text { sessions Cognitive } \\
\text { Behavioral Couples } \\
\text { Therapy } \\
10 \text { sessions Systemic } \\
\text { Couples Treatment at } \\
\text { Family Therapy Center }\end{array}$ & $\begin{array}{l}17 \text { couples } \\
21 \text { couples }\end{array}$ & $\begin{array}{l}\text { Significant decrease } \\
\text { in psychological } \\
\text { aggression for both } \\
\text { groups; no significant } \\
\text { pre-post difference in } \\
\text { physical aggression } \\
\text { for either group }\end{array}$ & CTS2 & 4 months \\
\hline $\begin{array}{l}\text { Woodin \& } \\
\text { O’Leary (in } \\
\text { press) }\end{array}$ & $\begin{array}{l}2 \mathrm{hr} \text { assessment and } 2 \mathrm{hr} \\
\text { motivational feedback } \\
\text { session } \\
2 \mathrm{hr} \text { assessment and } \\
\text { minimal, non-motivational } \\
\text { feedback session }\end{array}$ & $\begin{array}{l}25 \text { college } \\
\text { student } \\
\text { couples } \\
\\
25 \text { college } \\
\text { student } \\
\text { couples }\end{array}$ & $\begin{array}{l}\text { Motivational sessions } \\
\text { led to significantly } \\
\text { greater reduction in } \\
\text { physical aggression }\end{array}$ & $\begin{array}{l}\text { CTS2 (either } \\
\text { partner's } \\
\text { report of } \\
\text { violence) }\end{array}$ & 9 months \\
\hline $\begin{array}{l}\text { Fals-Stewart \& } \\
\text { Clinton- } \\
\text { Sherrod, } 2009\end{array}$ & $\begin{array}{l}\text { Behavioral Couples } \\
\text { Therapy for married or } \\
\text { cohabiting male substance- } \\
\text { abusing patients and their } \\
\text { partners (12 conjoint } \\
\text { sessions, } 20 \text { individual 12- } \\
\text { step sessions) } \\
\text { Individual-Based } \\
\text { Treatment for male } \\
\text { substance-abusing partner } \\
\text { only (32 individual 12-step } \\
\text { sessions) }\end{array}$ & $\begin{array}{l}103 \\
\text { couples }\end{array}$ & $\begin{array}{l}\text { BCT led to } \\
\text { significantly less } \\
\text { male-to female } \\
\text { violence compared to } \\
\text { IBT }\end{array}$ & $\begin{array}{l}\text { Male-to- } \\
\text { Female } \\
\text { Percentage of } \\
\text { Days with } \\
\text { Any } \\
\text { Violence }\end{array}$ & $\begin{array}{l}12 \\
\text { months }\end{array}$ \\
\hline $\begin{array}{l}\text { Circles of } \\
\text { Peace }\end{array}$ & $\begin{array}{l}\text { Circles of Peace (weekly } \\
\text { conferences with offender, } \\
\text { victim, family and } \\
\text { community members) } \\
\text { Batterer Intervention } \\
\text { Program }\end{array}$ & $\begin{array}{l}\text { Total } \mathrm{N}= \\
152 \\
\text { domestic } \\
\text { violence } \\
\text { offenders }\end{array}$ & $\begin{array}{l}\text { Clients in Circles of } \\
\text { Peace had } \\
\text { significantly fewer } \\
\text { arrests overall } \\
\text { No significant } \\
\text { difference in } \\
\text { domestic violence } \\
\text { arrests }\end{array}$ & $\begin{array}{l}\text { Arrest } \\
\text { records }\end{array}$ & $\begin{array}{l}24 \\
\text { months }\end{array}$ \\
\hline
\end{tabular}


QUASI-EXPERIMENTAL DESIGNS

\begin{tabular}{|c|c|c|c|c|c|}
\hline Author/Year & Treatment Approach & $\begin{array}{l}\text { Sample } \\
\text { Size }\end{array}$ & Outcome & $\begin{array}{l}\text { Outcome } \\
\text { Measure }\end{array}$ & $\begin{array}{l}\text { Follow- } \\
\text { up } \\
\text { Period }\end{array}$ \\
\hline $\begin{array}{l}\text { O’Farrell, } \\
\text { Murphy, } \\
\text { Stephan, Fals- } \\
\text { Stewart, } \\
\text { Murphy, } 2004\end{array}$ & $\begin{array}{l}\text { BCT for married or } \\
\text { cohabiting male alcoholics } \\
\text { and their partners ( } 10-12 \\
\text { individual couple sessions } \\
\text { followed by } 10 \text { couples } \\
\text { group sessions) } \\
\\
\text { Matched nonalcoholic } \\
\text { community sample }\end{array}$ & $\begin{array}{l}303 \\
\text { couples } \\
\\
303 \text { men; } \\
303 \text { women }\end{array}$ & $\begin{array}{l}\text { Significant } \\
\text { differences in partner } \\
\text { aggression between } \\
\text { groups at Pre-test, no } \\
\text { significant } \\
\text { differences between } \\
\text { groups by 2-year } \\
\text { follow-up } \\
\text { Significant reductions } \\
\text { in physical } \\
\text { aggression from Pre- } \\
\text { test to } 12 \text { month } \\
\text { follow up, and from } \\
\text { Pre-test to } 24 \text { month } \\
\text { follow up }\end{array}$ & $\begin{array}{l}\text { CTS (higher } \\
\text { of male or } \\
\text { female } \\
\text { report) }\end{array}$ & $1-2$ years \\
\hline $\begin{array}{l}\text { Schumm, } \\
\text { O’Farrell, } \\
\text { Murphy, Fals- } \\
\text { Stewart, } 2009\end{array}$ & $\begin{array}{l}\text { BCT for married and } \\
\text { cohabiting alcoholic } \\
\text { women and their partners } \\
\text { (10-12 individual couple } \\
\text { sessions followed by } 10 \\
\text { couples group sessions) } \\
\text { Matched nonalcoholic } \\
\text { community sample }\end{array}$ & $\begin{array}{l}103 \\
\text { couples } \\
\\
103 \text { men; } \\
103 \text { women }\end{array}$ & $\begin{array}{l}\text { Significant } \\
\text { differences in partner } \\
\text { aggression between } \\
\text { groups at Pre-test, no } \\
\text { significant } \\
\text { differences between } \\
\text { groups by 1-year } \\
\text { follow-up for } \\
\text { alcoholic patients } \\
\text { who had remitted } \\
\text { Significant reductions } \\
\text { in physical } \\
\text { aggression from Pre- } \\
\text { test to } 12 \text { month } \\
\text { follow up, and from } \\
\text { Pre-test to } 24 \text { month } \\
\text { follow up }\end{array}$ & $\begin{array}{l}\text { CTS (higher } \\
\text { of male or } \\
\text { female } \\
\text { report) }\end{array}$ & $1-2$ years \\
\hline
\end{tabular}

